\title{
PROBABILIDADE BAYESIANA E REGRESSÃO LOGÍSTICA NA AVALIAÇÃO DA SUSCEPTIBILIDADE DE OCORRÊNCIA DE INCÊNDIOS DE GRANDE MAGNITUDE
}

\author{
RAFAELlo V. Bergonse ${ }^{1}$ \\ JOÃO M. BIDARRA2
}

\begin{abstract}
Resumo - Este artigo tem por objectivo a aplicação de um modelo de susceptibilidade orientado para a aplicação a incêndios de grande magnitude, pequena parte do total de ocorrências que origina a grande maioria dos estragos anuais. Esta relação frequência/magnitude é característica dos regimes de fogo dos países do Sul da Europa. Com base na cartografia das áreas ardidas, no período 1990-2007 no distrito de Castelo Branco, é proposto um método de identificação dos incêndios de grande magnitude e são comparadas duas técnicas de integração de dados, assentes em Probabilidade Bayesiana e Regressão Logística. Os resultados mostram uma capacidade preditiva superior da técnica Bayesiana, e um ajustamento do modelo ao comportamento dos incêndios considerados de grande magnitude, por oposição a todos os incêndios. Embora deva ser alvo de desenvolvimentos futuros, o modelo proposto pretende complementar outras formas de avaliação da susceptibilidade/perigosidade, salientando as áreas onde tendem a concentrar-se os incêndios mais danosos.
\end{abstract}

Palavras-chave: Incêndios de grande magnitude, susceptibilidade, probabilidade bayesiana, regressão logística.

\begin{abstract}
BAYESIAN PROBABILITY AND LOGISTIC REGRESSION IN THE ASSESSMENT OF THE SUSCEPTIBILITY TO HIGH MAGNITUDE WILDFIRES: AN APPLICATION TO CASTELO BRANCO DISTRICT. The aim of this paper is to apply a susceptibility model to high magnitude wildfires - with the latter defined as the small fraction of the total number of occurrences that causes most of the annual damage. This type of frequency/ magnitude relation is characteristic of wildfire regimes in southern European countries. Drawing on the analysis of burnt-area maps for the period 1990-2007 in the Castelo Branco district, a wildfire classification method is put forth and a model is tested using two alternative data integration techniques: one based on Logistic Regression, the other on Bayesian probability. The results indicate that the Bayesian technique has slightly greater predictive capability and confirm that the proposed model is adjusted to the behaviour of wildfires considered to be of high magnitude. Although
\end{abstract}

Recebido: 03/06/2009. Aceite: 09/02/2010.

1 Bolseiro de doutoramento; Centro de Estudos Geográficos, IGOT.

E-mail: rafaellobergonse@gmail.com

2 Instituto Geográfico Português. E-mail: jmbidarra@gmail.com 
the suggested model may usefully undergo future improvements in order to increase its predictive capability, it can already be used to complement other forms of susceptibility/hazard analysis, by highlighting the areas that are most likely to be affected by the most destructive wildfire events.

Key-words: High magnitude wildfires, susceptibility, Bayesian probability, logistic regression.

Résumé - COMPARAISON ENTRE LA PROBABILITÉ BAYÉSIENNE ET LA RÉGRESSION LOGISTIQUE POUR L'ÉVALUATION DE LA SUSCEPTIBILITÉ À L'APPARITION D'INCENDIES DE grande magnitude. Application au district de Castelo Branco. On cherche à mettre au point un modèle applicable aux incendies de grande magnitude qui, en dépit de leur rareté, causent la plus grande part des dégâts annuels. Ce rapport fréquence/ magnitude est caractéristique du régime des incendies dans l'Europe du Sud. En se basant sur la cartographie des surfaces brûlées pendant la période 1990-2007 dans le district de Castelo Branco, on propose une méthode d'identification de ces incendies, en comparant deux techniques d'intégration des données. La technique de probabilité bayésienne présente une capacité prédictive supérieure à celle de la régression logistique et permet ainsi de mieux adapter le modèle présenté à ce type d'incendies. Ce modèle devra être amélioré, mais il permet déjà de mieux évaluer le rapport susceptibilité /danger et de reconnaitre les lieux où les incendies qui causent le plus de dommages tendent à se concentrer.

Mots-clés: Incendies de grande magnitude, susceptibilité, probabilité bayésienne, régression logistique.

\section{INTRODUÇÃO}

O ritmo anual de temperatura e de precipitação característico do clima mediterrânico é o principal factor potenciador do regime de fogo que afecta os países do Sul da Europa: Portugal, Espanha, França, Itália e Grécia (Pyne, 2006; Ventura e Vasconcelos, 2006). A alternância entre chuvas invernais e tempo seco estival potencia um ciclo particular de crescimento e combustão de biomassa, que constitui um factor diferenciador destes países face aos da Europa Central, com menor propensão natural para a ocorrência de incêndios (Pyne, 2006).

Dos cinco países referidos, Portugal é o mais pequeno e, desde o início dos anos 80, o que tem sofrido estragos mais severos. A análise realizada por Vieira (2006) revela que, no período entre 1981 e 2005, foi com frequência o que registou a maior proporção anual de área ardida. Considerando globalmente o período 1980-2004, foi de longe o país com maior número de fogos por hectare e a maior densidade de área queimada (Pereira et al., 2006). A evolução destes valores ao longo dos últimos anos justifica a consideração, patente na Proposta Técnica do Plano Nacional de Defesa Contra Incêndios (ISA, 2005a), de que "Enquanto naqueles países [restantes países do sul da Europa] os valores parecem estar estabilizados, Portugal apresenta uma forte e preocupante tendência de agravamento da situação". 
A análise da cartografia de áreas queimadas produzida anualmente durante o período 1990-2004 pelo Instituto Superior de Agronomia (ISA), no âmbito de uma parceria com a Direcção-Geral dos Recursos Florestais (DGRF) ${ }^{3}$, permite diferenciar padrões espaciais de área ardida no território continental português, conforme descrito por Pereira et al. (2006). O maior número de incêndios por concelho ocorre nos distritos de Braga, Porto e Lisboa. No entanto, estas ocorrências são responsáveis por uma percentagem muito reduzida da área queimada anual à escala do Continente, contrastando com a região que inclui os distritos de Viseu, Guarda, o interior de Coimbra e de Leiria, o limite Oeste de Castelo Branco e o Norte de Santarém, que é particularmente afectada por "grandes incêndios", assim considerados quando ultrapassam o limiar crítico de área ardida de 100 ha (ISA, 2005).

Subjacente a esta dicotomia entre áreas com mais ocorrências e áreas com mais área ardida está uma variedade de diferentes padrões espaciais, resultado dos múltiplos factores que se conjugam para produzir a ignição inicial e todo o processo subsequente de alargamento da área queimada, eventual reprodução, contenção e derradeira extinção, fases que caracterizam a evolução de um incêndio, à semelhança do ciclo de vida de um ser vivo (Ventura e Vasconcelos, 2006). Estes factores são de diferente natureza, tendo expressão espacial e temporal e interligando-se de forma complexa. A fim de simplificar o fenómeno com vista à sua modelação, pode-se conceber um incêndio em termos de um sistema, no qual várias componentes se articulam para produzir um output: uma determinada superfície ardida. Estas componentes combinam-se para produzir ignições (incendiarismo, realização de queimadas), para originar melhores ou piores condições para a evolução e propagação do fogo, ou seja, determinar o seu ambiente (condições meteorológicas, propriedades do combustível, condições topográficas), e para permitir que essa evolução se dê durante mais ou menos tempo (existência e eficiência de meios de prevenção, detecção e combate). Através do território continental português, estes factores interagem de diferentes formas, desaconselhando a construção de raciocínios baseados em valores médios nacionais (Pereira et al., 2006).

$\mathrm{O}$ fenómeno dos incêndios florestais ${ }^{4}$ é, em Portugal, caracterizado por uma relação particular entre frequência e proporção da área total ardida, que se estende à generalidade dos ecossistemas boreais e temperados e a muitas regiões tropicais, sendo marcada pelo facto de a grande maioria da área ardida durante um dado período resultar de uma proporção muito reduzida de eventos (Strauss et al., 1989). Estes últimos mantêm uma relação muito significativa com as condições meteorológicas; de facto, durante o período $1980-2000,80 \%$ da área ardida foi devida

3 Actualmente, a DGRF foi substituída pela Autoridade Florestal Nacional. A cartografia encontra-se disponível em http://www.afn.min-agricultura.pt/portal/dudf/informacoes/cartografia/ mapas-de-areas-ardidas.

4 Um incêndio considera-se florestal quando decorre em terrenos ocupados com arvoredos florestais, uso silvo-pastoril ou incultos de longa duração, sendo todos estes tipos de ocupação abrangidos pela designação espaço florestal. No presente trabalho utiliza-se esta designação oficial (ISA, 2005b). É porém de salientar que, como refere Pereira et al. (2006), 56\% da área ardida entre 1990 e 2005 correspondeu a matos, pelo que seria mais correcto falar de incêndios rurais. 
a fogos que tiveram lugar apenas em $10 \%$ dos dias, sendo esses dias marcados por padrões de escala sinóptica específicos (Ramos e Ventura, 1992; Pereira et al., 2005). A importância do contexto atmosférico está na origem de índices compostos como o FWI (Fire Weather Index) canadiano, que pretende modelar o teor de humidade dos combustíveis e o próprio comportamento do fogo com base em poucos parâmetros meteorológicos. Viegas et al. (2004) utilizaram unicamente o índice de secura (Drought Code; um dos três sub-índices do FWI que caracterizam o estado de humidade dos combustíveis), calculado para a estação meteorológica de Coimbra, para explicar quase $70 \%$ da variação inter-anual da área queimada em Portugal Continental durante o período 1987-2000.

A concentração dos estragos em poucos eventos origina dificuldades ao planeamento do sistema de combate aos incêndios, associadas aos custos e complicações logísticas necessários à manutenção de um dispositivo preparado durante todo o período anual considerado crítico (1 de Julho a 30 de Setembro), para fazer face a eventos que têm lugar em poucos dias. Porém, ao contrário das medidas de combate, as medidas preventivas não apresentam a mesma vulnerabilidade, já que podem ser diferidas no tempo face à ocorrência de incêndios. Esta é, segundo Pereira et al. (2006), uma forte razão para as privilegiar.

O objectivo do presente trabalho foi a comparação de duas técnicas de integração de dados, assentes em Probabilidade Bayesiana e na Regressão Logística, incorporadas num modelo de distribuição espacial da susceptibilidade à ocorrência de incêndios de grande magnitude, ou seja, a pequena parte do total anual de ocorrências que origina a grande maioria da área ardida.

A metodologia foi operacionalizada em ambiente SIG, segundo uma estrutura de dados matricial, tendo como área de estudo o distrito de Castelo Branco.

$\mathrm{O}$ trabalho divide-se em seis partes. Na primeira é enquadrada conceptualmente a problemática da susceptibilidade, subjacente a toda a metodologia utilizada. $\mathrm{Na}$ segunda é apresentada a estrutura do modelo. Na terceira parte, a área de estudo é caracterizada com respeito às variáveis espaciais utilizadas e ao padrão de áreas ardidas observado no período a que se referem os dados. Na quarta são descritas as formas de classificação aplicadas aos temas cartográficos e as duas técnicas de integração de dados utilizadas. Na quinta parte são descritos e validados os resultados obtidos, sendo as conclusões tecidas na sexta parte.

\section{ENQUADRAMENTO CONCEPTUAL}

Conceitos como "Risco" e "Perigo" têm sido utilizados com diversos significados por diferentes autores no contexto do estudo da ocorrência de incêndios florestais em Portugal. Esta ambivalência resulta da diversidade de formação dos autores que lidam com o fenómeno e, consequentemente, dos seus interesses específicos. Num contexto real de tomada de decisão, porém, a ausência de uma terminologia comum pode levar a interpretações erróneas, com consequências fatais (Bachmann e Allgower, 1999). No presente trabalho, foi utilizado o enquadramento 
conceptual proposto por estes dois autores, também já adoptado por Pereira e Santos (2003) e Verde e Zêzere (2007). O modelo assume o risco como "a probabilidade de que um incêndio florestal ocorra num local específico, sob determinadas circunstâncias, e as suas consequências esperadas, caracterizadas pelos impactes nos objectos afectados", na tradução de Pereira e Santos (2003). Este conceito resulta da articulação de dois parâmetros: a probabilidade de ocorrência do evento perigoso numa dada área e num dado período de tempo (Perigosidade); e o grau de destruição e as perdas económicas associadas à acção do fenómeno sobre os objectos (casas, culturas) presentes na área (Dano Potencial). A Perigosidade resulta, por sua vez, da articulação de duas dimensões: a espacial, denominada Susceptibilidade (propensão da área ou unidade territorial para ser afectada pelo fenómeno, avaliada a partir das suas propriedades intrínsecas) e a temporal, denominada Probabilidade, definida como a verosimilhança de que o evento considerado ocorra durante um determinado período de referência (Verde, 2008).

Para além do contexto terminológico, a simplificação da realidade que está inerente à construção de qualquer modelo, de perigosidade ou não, pressupõe a selecção de um conjunto de objectos e processos considerados relevantes para o fim a atingir (Longley et al., 2005). A este respeito, os modelos de risco/perigosidade podem ser estruturados em duas grandes categorias (Verde, 2008): modelos dinâmicos, associados sobretudo a aspectos meteorológicos correlativos com o comportamento do fogo, como o vento ou a temperatura; e modelos estruturais, que consideram a favorabilidade do território à ocorrência de incêndios em função de variáveis espaciais (declive, exposição, ocupação do solo, altitude, etc.).

Exemplos dos primeiros são os índices meteorológicos propostos por Ramos e Ventura (1992), Lourenço (2004) ou o já referido FWI, adaptado à realidade nacional por Viegas et al. (2004) combinado com probabilidade Bayesiana por Durão e Soares (2007). Exemplos estruturais são o modelo proposto por Chuvieco e Congalton (1989), aquele que esteve subjacente à produção da recente Cartografia de Risco de Incêndio (CRIF) pelo Instituto Geográfico Português (IGP, 2008) ambos recorrendo à soma ponderada para a integração das diferentes variáveis ${ }^{5}$, e o modelo de Perigosidade recentemente proposto por Verde e Zêzere (2007).

\section{ESTRUTURA DO MODELO}

O modelo proposto neste trabalho é de tipo estrutural e pretende, com base nas áreas ardidas em incêndios considerados de grande magnitude durante um período de referência de $N$ anos, prever o padrão de áreas ardidas para os $n$ anos

5 Embora os modelos dinâmicos pressuponham uma escala de análise temporal reduzida, diária ou mesmo horária, caso do FWI, a utilização de variáveis atmosféricas à escala da normal climatológica permite convertê-las em variáveis estruturais. É o caso do número anual de dias com temperatura superior a $25^{\circ} \mathrm{C}$, utilizado por Pereira e Santos (2003). 
seguintes. Os parâmetros $N$ e $n$ foram definidos em função dos dados geográficos disponíveis, sendo utilizados para modelação os doze anos de 1990 a 2001 $(N=12)$, com os seis anos de 2002 a 2007 reservados para validação $(n=6)$.

São considerados apenas os incêndios de grande magnitude (IGM), em função da já referida distribuição característica da maioria do dano anual por um número reduzido de ocorrências (Strauss et al., 1989; Pereira et al., 2006). O limiar de área ardida que define estes incêndios (cuja metodologia de determinação é descrita no ponto 4) variará segundo o regime de fogo dominante em cada região, pretendendo-se assim, por um lado, adequar o modelo a um uso de âmbito regional, e por outro evitar a generalização que advém do estabelecimento de um valor rígido (caso dos 100 ha oficialmente convencionados para definir os grandes incêndios florestais), forçosamente desajustado a regiões com padrões de área ardida anual muito diferentes.

Foram utilizadas apenas duas variáveis espaciais, consideradas as mais significativas no contexto estudado, conforme Chuvieco e Congalton (1989), IGP (2004, na construção da Carta de Risco de Incêndio) e Verde e Zêzere (2007), na previsão da perigosidade à escala do Continente: o declive e a ocupação do solo. Significativamente, Verde (2008) testou a sua importância à escala do Continente, conjuntamente com várias outras ${ }^{6}$ concluindo, por um lado, que a integração de muitas variáveis não apresenta vantagens e, por outro, que as variáveis meteorológicas devem ser consideradas no contexto diário, e não numa perspectiva estrutural.

A figura 1 apresenta as variáveis utilizadas e a forma como se articulam.

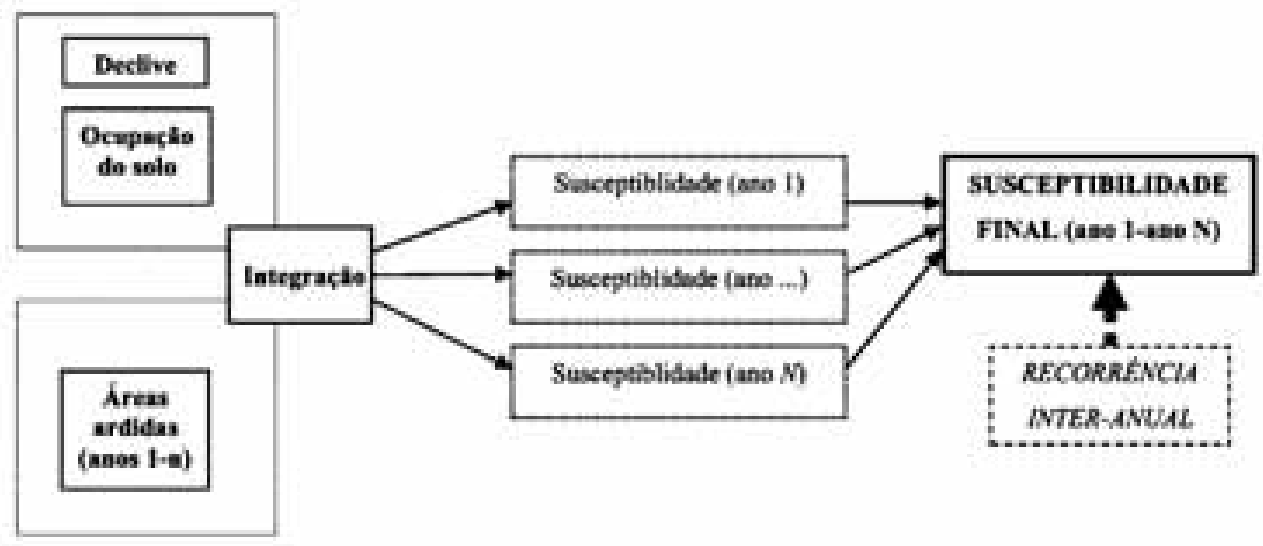

Fig.1 - Esquema operacional do modelo de susceptibilidade proposto.

Fig 1 - Operational scheme of the suggested susceptibility model.

6 Altitude, precipitação média anual, número de dias com temperatura mínima $\geq 20^{\circ} \mathrm{C}$, número de dias com temperatura máxima $>25^{\circ} \mathrm{C}$, e número de dias com precipitação $\geq 1 \mathrm{~mm}$ entre Maio e Setembro. 
Através da integração dos mapas referentes às variáveis independentes com as áreas ardidas em IGM em cada um dos 12 anos do período de modelação obtém-se, para cada classe $i$ de cada tema $j$ (declive ou ocupação do solo), 12 valores de susceptibilidade anual, formalmente $S_{\text {anual }} T i j$.

A susceptibilidade final, $S_{\text {final }}$ Tij, resulta da integração dos valores anuais, através do cálculo da sua média simples.

$$
S_{\text {final }} \text { Tij }=\frac{\sum_{a 1}^{a N} S_{\text {anual }} T i j}{N}
$$

\section{A ÁREA DE ESTUDO}

$\mathrm{Na}$ distribuição espacial das variáveis independentes pelo distrito de Castelo Branco, bem como na área ardida no período a que se referem os dados (1990-2007), observa-se uma clara diferenciação entre o sector Oeste e o sector Leste (figs. 2 a 5).

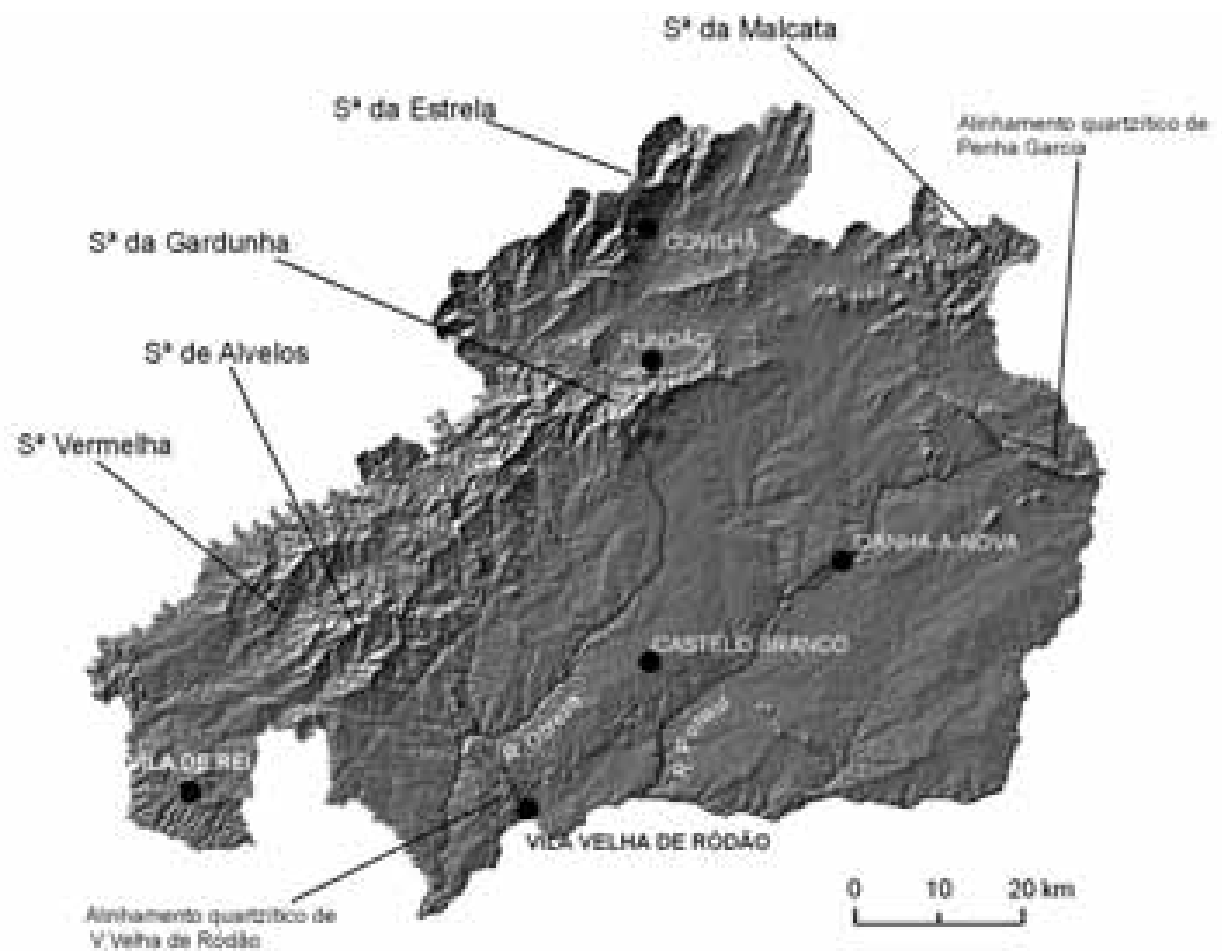

Fig. 2 - Principais formas de relevos e localidades na área de estudo.

Fig. 2 - Main morphological features and localities in the study area. 


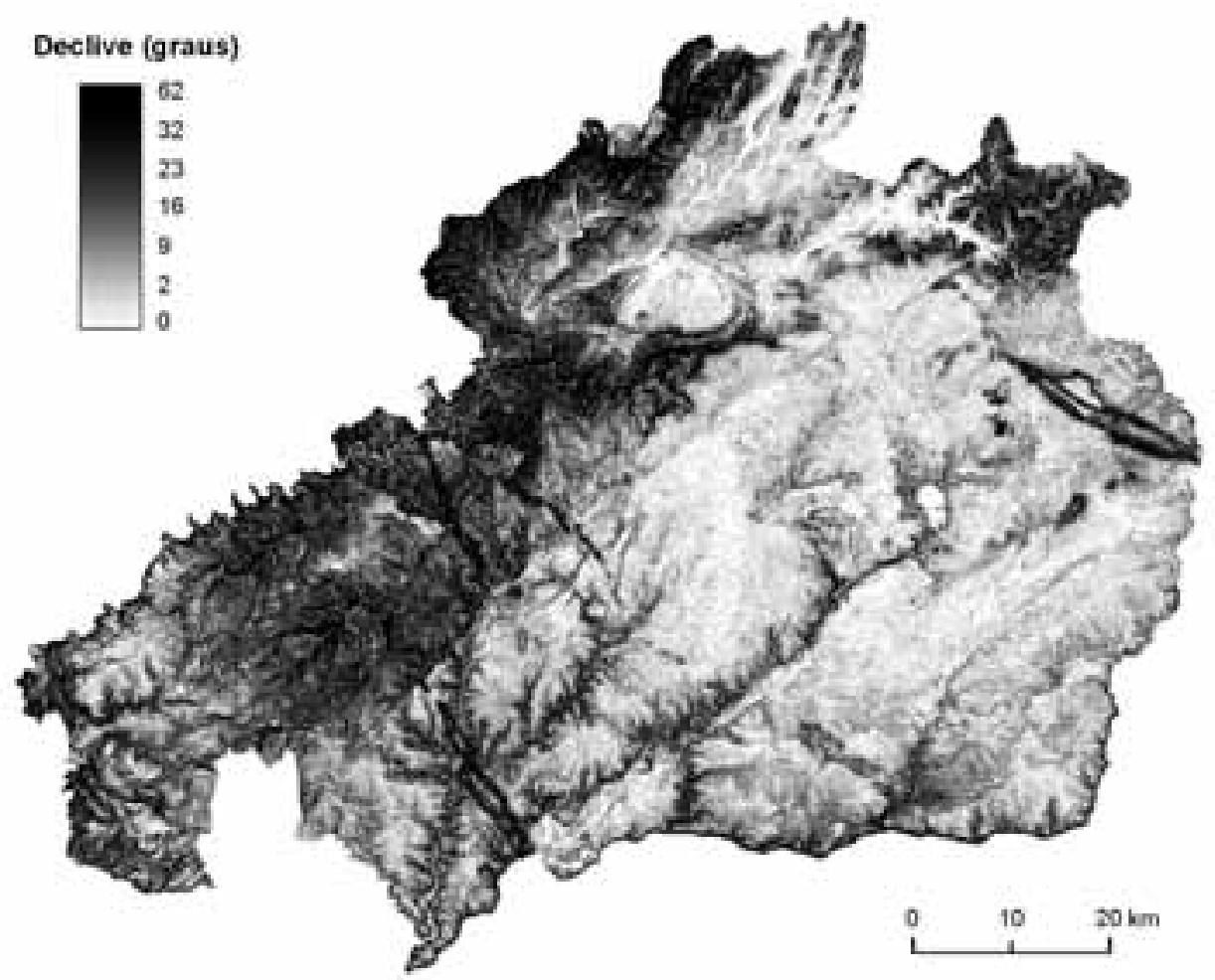

Fig. 3 - Declive.

Fig. 3 - Slope gradient

Os declives mais acentuados (fig. 3) concentram-se no sector Oeste, acompanhando em grande medida a orientação SW-NE dos relevos representados pelas serras Vermelha, de Alvelos e da Gardunha, bem como pela Serra da Estrela, no limite NW do distrito (fig. 2). No sector oriental, correspondente, no contexto geomorfológico, à plataforma de Castelo Branco, os valores mais elevados situam-se ao longo dos cursos do Rio Pônsul e da Ribeira da Ocreza, e nos alinhamentos quartzíticos de Penha Garcia e Vila Velha de Ródão.

O padrão de ocupação do solo (quadro I, classes predominantes na figura 4) está também fortemente relacionado com a topografia. De acordo com a classificação CORINE Land Cover, predominam no sector $\mathrm{W}$ as florestas de resinosas (classe 312 , cerca de $22 \%$ da área total do distrito), intercaladas com manchas importantes de outras ocupações (caso dos matos, classe 322, nas áreas elevadas da Serra da Gardunha, bem como na da Malcata, no NE do distrito). As manchas de usos agrícolas (nível 2) são apenas pequenos retalhos no sector montanhoso, mas predominam no relevo suave do sector Oriental. Do total do distrito por elas ocupado, 9\% são constituídos por culturas anuais de sequeiro (211), sendo esta a classe agrícola dominante. 


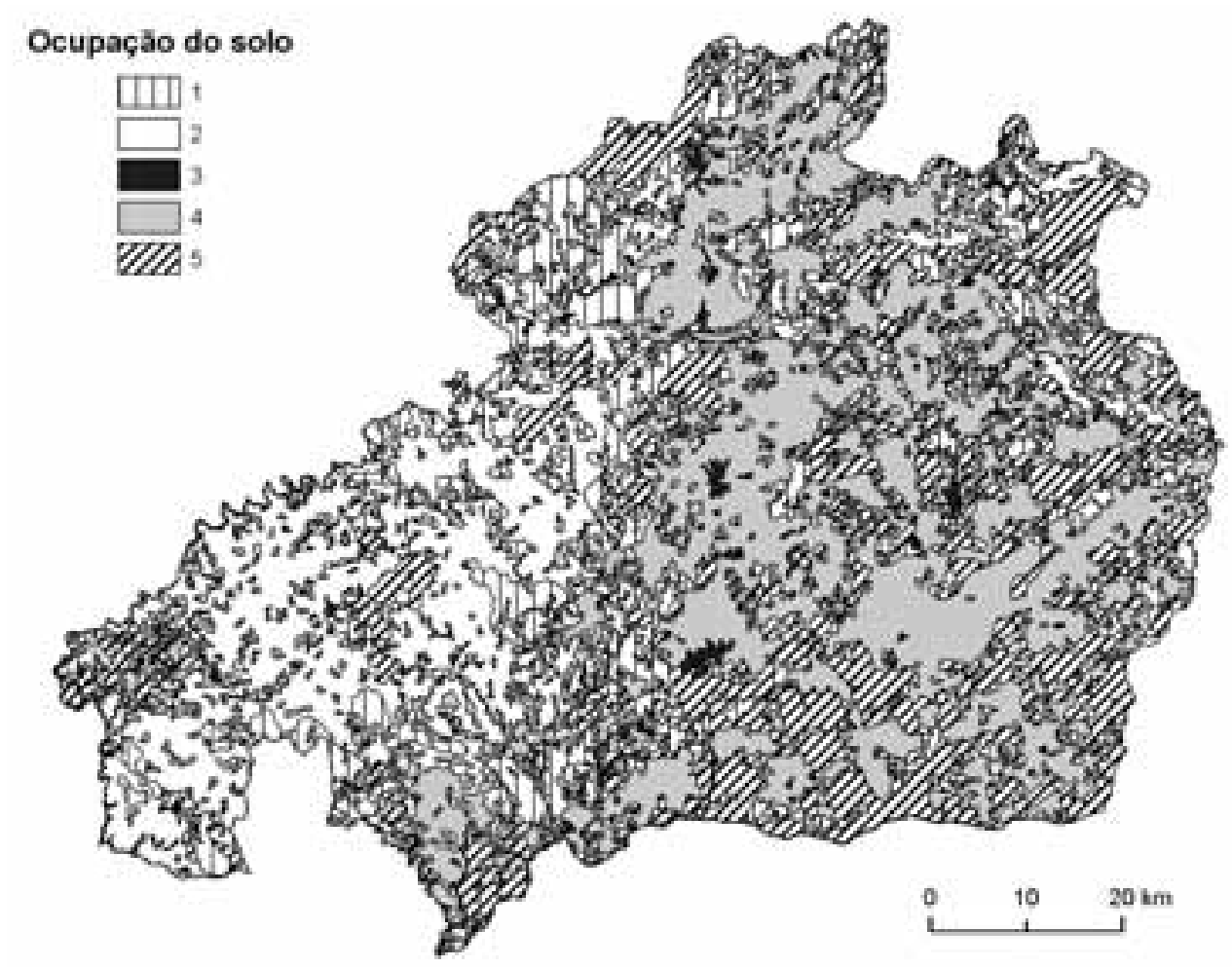

Fig. 4 - Principais classes de ocupação do solo.

1. Espaços florestais degradados, cortes e novas plantações; 2. Florestas de resinosas; 3. Área não considerada; 4. Áreas agrícolas; 5. Áreas florestais e semi-naturais.

Fig. 4 - Main land use classes.

1 - Transitional woodland/shrub; 2 - Coniferous forest;

3 - Areas not considered; 4 - Agricultural areas; 5 -Other forest and semi-natural areas

Ao contrário das resinosas, já referidas, as florestas de folhosas (311) concentram-se nos extremos SE e E do distrito, sempre em alternância com os usos agrícolas.

Por último, a classe 324, "Espaços Florestais Degradados, Cortes e Novas Plantações" encontra-se presente em retalhos por toda a área de estudo, concentrando-se, porém, numa mancha de configuração linear e orientação sensivelmente S-N, entre Vila Velha de Ródão e a Serra da Estrela.

As áreas ardidas (fig. 5) concentram-se no sector Ocidental da área de estudo, acompanhando, tal como os declives, a orientação do relevo. Embora a sua concentração seja muito menor no sector Oriental, há manchas ardidas significativas presentes, nomeadamente a W de Vila Velha de Ródão, a E de Castelo Branco, e em torno de Idanha-a-Nova. 


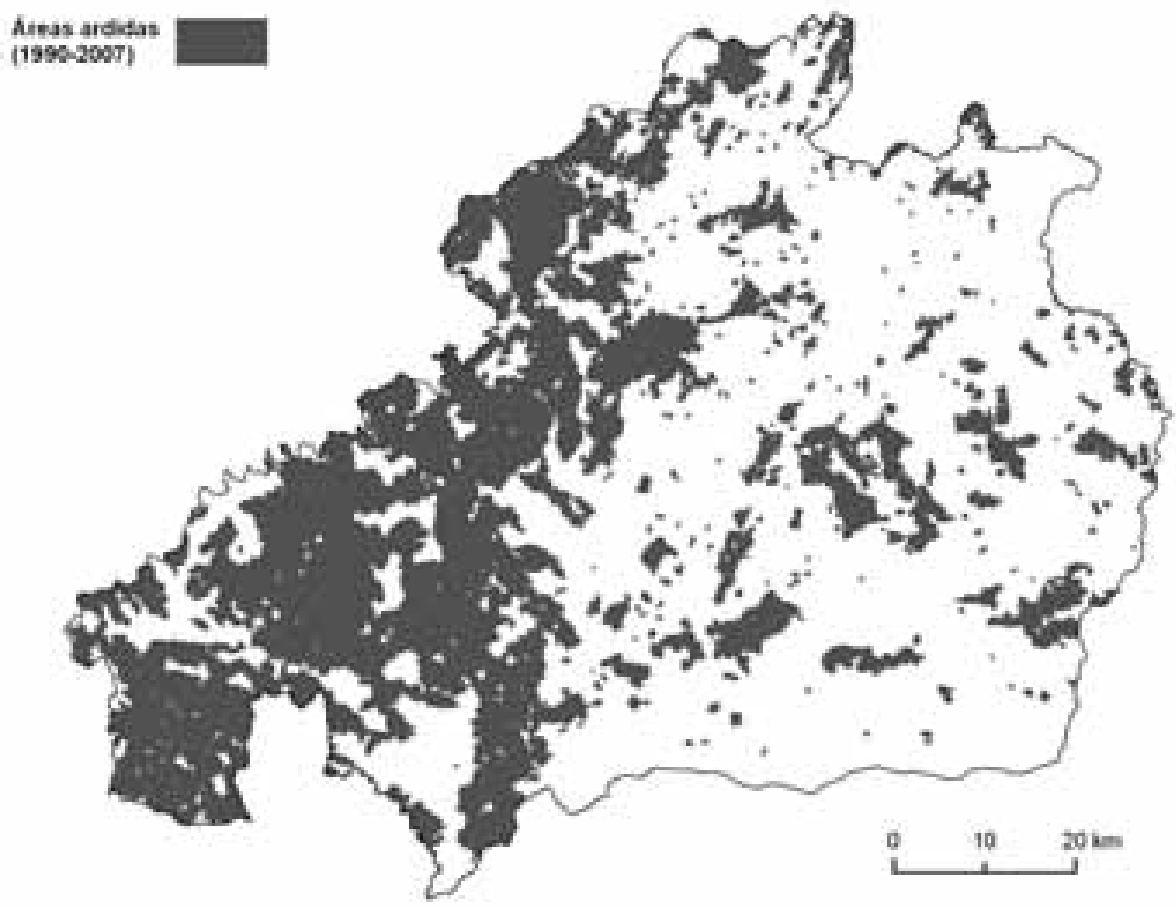

Fig. 5 - Áreas ardidas no período 1990-2007.

Fig. 5 - Burnt areas during the period 1990-2007.

Quadro I - Proporção relativa de cada classe de Ocupação do Solo e Declive na área de estudo. Table I - Relative importance of the various land-use and slope-gradient classes in the study area.

\begin{tabular}{|c|c|c|c|c|}
\hline $\begin{array}{l}\text { Cód. Classe } \\
\text { CLC } 2000\end{array}$ & Designação da classe & $\begin{array}{l}\% \text { da } \\
\text { área } \\
\text { total }^{7}\end{array}$ & $\begin{array}{c}\text { Classe } \\
\text { de Declive } \\
\left({ }^{\circ}\right)\end{array}$ & $\%$ da área total \\
\hline 100 & Tecido urbano & 0,6 & \multirow{3}{*}[0-2]{} & \multirow{3}{*}{20,4} \\
\hline 211 & $\begin{array}{l}\text { Culturas anuais } \\
\text { de sequeiro }\end{array}$ & 9,2 & & \\
\hline 212 & $\begin{array}{l}\text { Culturas anuais } \\
\text { de regadio }\end{array}$ & 1,7 & & \\
\hline 221 & Vinhas & 0,3 & \multirow{5}{*}{ [2-9] } & \multirow{5}{*}{39,9} \\
\hline 222 & Pomares & 0,8 & & \\
\hline 223 & Olivais & 4 & & \\
\hline 231 & Pastagens & 0,1 & & \\
\hline 241 & $\begin{array}{l}\text { Culturas anuais } \\
\text { associadas a culturas } \\
\text { permanentes }\end{array}$ & 1,5 & & \\
\hline
\end{tabular}




\begin{tabular}{|c|c|c|c|c|}
\hline $\begin{array}{l}\text { Cód. Classe } \\
\text { CLC } 2000\end{array}$ & Designação da classe & $\begin{array}{l}\% \text { da } \\
\text { área } \\
\text { total }^{7}\end{array}$ & $\begin{array}{c}\text { Classe } \\
\text { de Declive } \\
\left({ }^{\circ}\right)\end{array}$ & $\%$ da área total \\
\hline 242 & $\begin{array}{l}\text { Sistemas culturais } \\
\text { e parcelares complexos }\end{array}$ & 6,9 & \multirow{3}{*}{ [9-16] } & \multirow{3}{*}{21,3} \\
\hline 243 & $\begin{array}{l}\text { Agricultura com espaços } \\
\text { naturais }\end{array}$ & 7,9 & & \\
\hline 244 & Sistemas agro-florestais & 4,1 & & \\
\hline 311 & Florestas de folhosas & 12,3 & \multirow{5}{*}{ ]16-23] } & \multirow{5}{*}{12,7} \\
\hline 312 & Florestas de resinosas & 21,7 & & \\
\hline 313 & Florestas mistas & 2,3 & & \\
\hline 321 & Pastagens naturais & 1,8 & & \\
\hline 322 & Matos & 3,8 & & \\
\hline 323 & Vegetação esclerofítica & 0,5 & \multirow{3}{*}{ [23-32] } & \multirow{3}{*}{5,2} \\
\hline 324 & $\begin{array}{l}\text { Espaços florestais } \\
\text { degradados, cortes } \\
\text { e novas plantações }\end{array}$ & 18,5 & & \\
\hline 332 & Rocha nua & 0,2 & & \\
\hline 333 & Vegetação esparsa & 0,7 & \multirow{3}{*}{ ]32-64] } & \multirow{3}{*}{0,5} \\
\hline 334 & Áreas ardidas & 0,9 & & \\
\hline 500 & Áreas aquáticas & 0,6 & & \\
\hline
\end{tabular}

\section{METODOLOGIA UTILIZADA}

O declive, em graus, foi obtido a partir de um Modelo Digital de Terreno de tipo TIN $^{8}$, triangulado a partir da altimetria da Carta Militar de Portugal na escala 1:25 000 (IGeoE), e convertido para estrutura matricial, com um pixel de $30 \mathrm{~m}$ de lado9 . Em função da progressão tendencialmente linear do valor de declive face à frequência de ocorrência, observado num histograma, as classes foram definidas com base na posição dos desvios-padrão, com os seguintes limites: $\left[0-2^{\circ}\right] ;\left[2-9^{\circ}\right] ;\left[9-16^{\circ}\right] ;\left[16-23^{\circ}\right] ;\left[23-32^{\circ}\right]$ e $\left[32-63^{\circ}\right]$. O valor máximo é de $62,3^{\circ}$ e o mínimo 0 , com a média situada nos $8,8^{\circ}$ e o desvio-padrão nos $7,6^{\circ}$.

A ocupação do solo foi obtida a partir da carta CORINE Land Cover 2000, da responsabilidade da Agência Europeia do Ambiente, produzida numa escala de 1:100 000. Esta informação sofre inevitavelmente de alguma desactualização, uma vez que o conjunto de anos utilizado para modelação e validação do modelo

$7 \mathrm{O}$ distrito possui uma área total aproximada de $6628 \mathrm{Km}^{2}$.

8 Triangulated Irregular Network.

9 Esta resolução foi escolhida por ser a mesma das imagens Landsat, que serviram de base à cartografia de áreas ardidas utilizada, resultante da parceria ISA/IGP. 
começa 10 anos antes da data da sua produção, e termina 7 anos depois. Esta desactualização é acentuada pela sucessão vegetal a que a ocorrência de um incêndio dá origem, fazendo com que uma dada área possa passar por várias tipologias de coberto durante o período a que se reportam os dados (e portanto por diferentes níveis de susceptibilidade), sem que tal seja considerado. Face a esta condicionante, assumiu-se como hipótese de trabalho que as áreas sujeitas a estas transições não consideradas em cada classe de ocupação não são suficientemente significativas, face à área total da classe, para comprometer os resultados.

A informação de área ardida foi obtida a partir da cartografia anual produzida pela parceria ISA/DGRF. Embora a área ardida mínima cartografada não tenha sido constante, tendo sido de 25 ha entre 1990-1992, de 15 ha em 1993 e 1994 e de 5ha a partir de 1995, toda a informação foi actualizada em 2008, sendo actualmente disponibilizada com uma área mínima de 5ha para os 18 anos do período $1990-2007^{10}$.

\section{Identificação de Incêndios de Grande Magnitude (IGM)}

A fim de determinar o limiar de área ardida que caracteriza os IGM, a relação entre proporção acumulada de área e de manchas ardidas foi representada, para cada um dos anos entre 1990-2007, num gráfico de dispersão (fig. 6), com as manchas ardidas consideradas por ordem crescente de dimensão. Para determinar a quebra na distribuição que define a separação entre IGM e os restantes

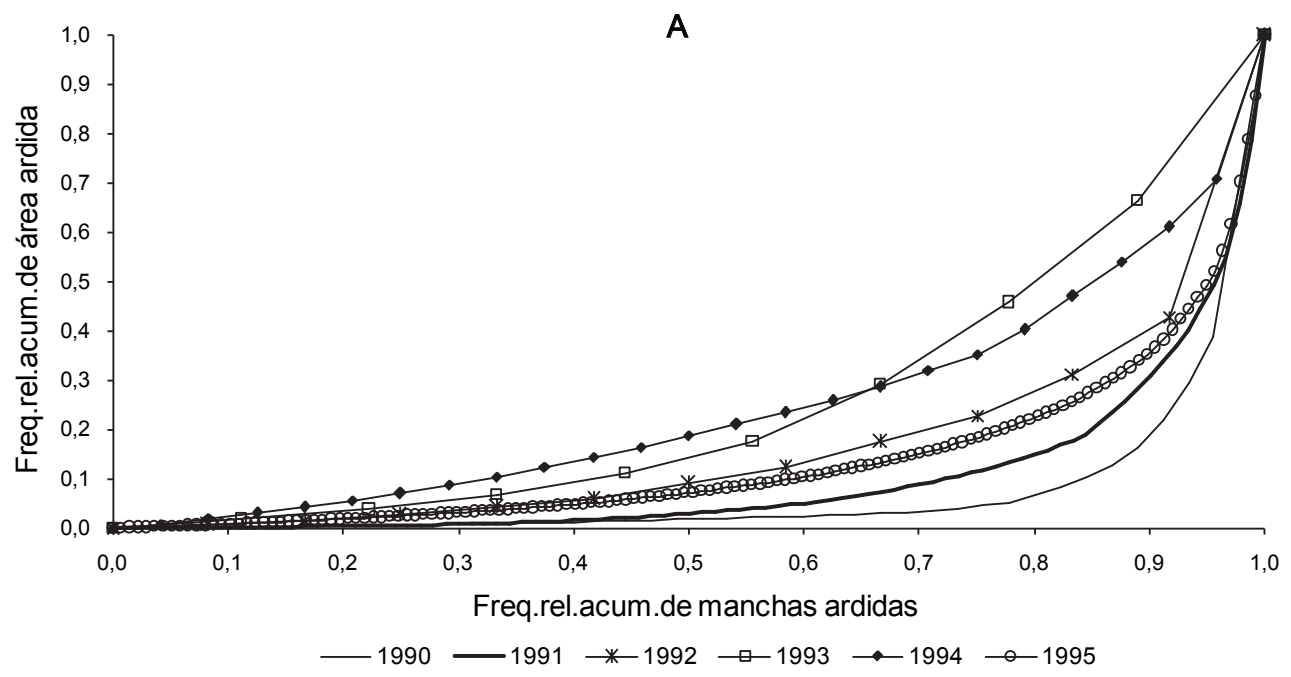

10 É importante considerar que esta informação descreve áreas ardidas contínuas, e não áreas ardidas em incêndios individuais. Embora seja possível que algumas grandes manchas ardidas resultem da coalescência de muitos pequenos incêndios, considerou-se válido o seu uso, assumindo-se que, a ter ocorrido, essa coalescência denota uma propensão elevada para arder. 


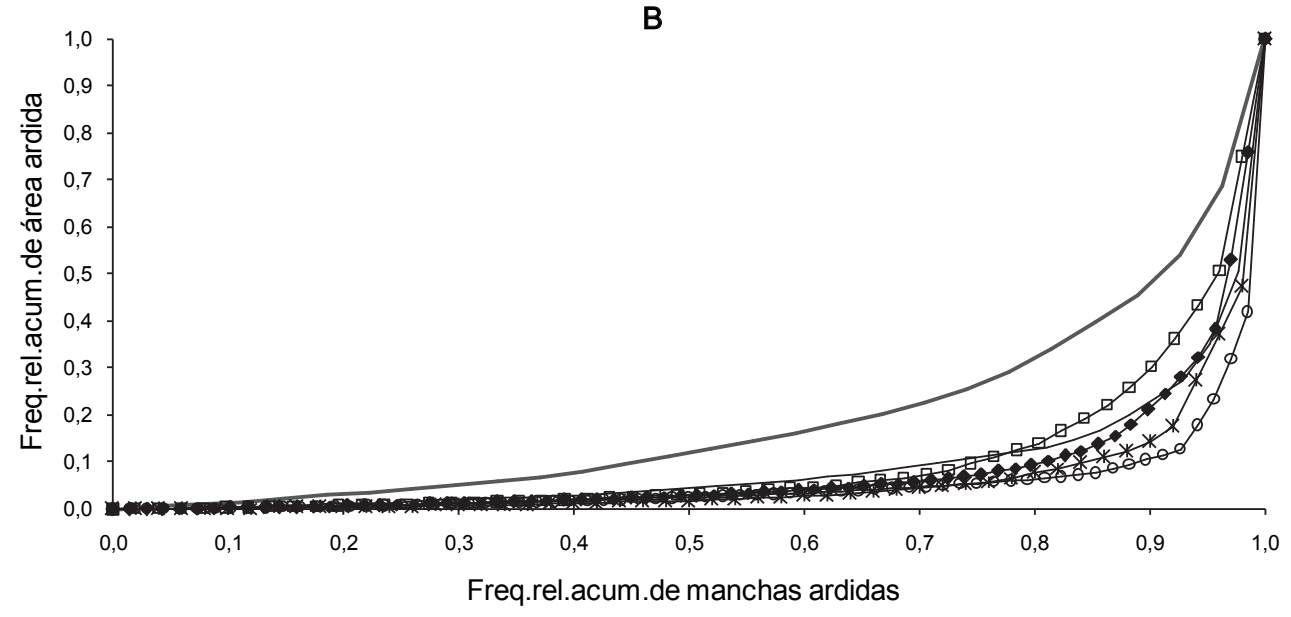

$-1996-1997 \rightarrow 1998 \rightarrow 1999 \multimap-2000 \multimap 2001$

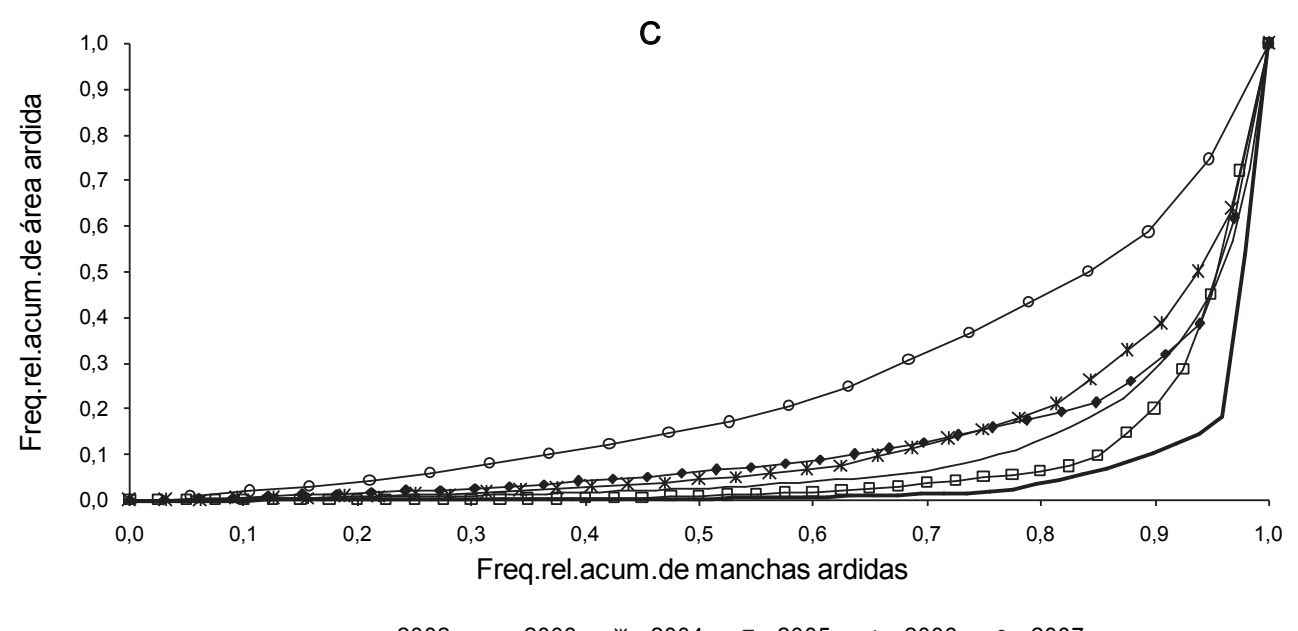

Fig. 6 - Relação entre proporção relativa acumulada de manchas ardidas contínuas e área ardida, para os períodos de 1990-1995 (A), 1996-2001 (B) e 2002-2007 (C).

Fig. 6 - Relation between the accumulated relative proportion of continuous burnt patches and the burnt area, in the periods 1990-1995 (A), 1996-2001 (B) and 2002-2007 (C). 
incêndios, foi calculada a diferença entre os valores de declive das rectas definidas por pares sucessivos de pontos, descrevendo cada ponto a relação entre a frequência relativa referente a uma mancha ardida individual e a área ardida relativa acumulada que lhe corresponde. Para cada par de pontos $(x 1, y 1) ; x 2, y 2)$, foi calculado o valor de $\Delta y$, ou seja, (y2-y1), já que a progressão em $x$ é constante, na forma de uma razão de $1 /$ total de ocorrências consideradas, sendo depois calculadas as diferenças entre os valores de $\Delta y$ apresentados por rectas sucessivas, ou seja, $(y 3-y 2)-(y 2-y 1)$.

A partir da análise destas diferenças, procurou definir-se para cada ano qual o ponto que marca a transição entre o sector inicial da curva (mais próximo da horizontal) e o seu sector final (mais próximo da vertical). Este ponto será aquele que os dois sectores das rectas cuja diferença entre os declives é superior face às diferenças anteriores e posteriores. $\mathrm{O}$ valor de área ardida associado a um incêndio particular corresponderá ao limite a partir do qual se define o conjunto de incêndios responsáveis pela maioria dos IGM nesse ano.

O carácter quantitativo deste método pretende reduzir a arbitrariedade associada à simples observação das curvas.

A caracterização geral das manchas ardidas associadas a IGM em cada um dos anos é apresentada no quadro II. Embora seja evidente a tendência para uma parte muito significativa da área ardida se concentrar em poucas ocorrências, os anos de 1993, 1994, 1997 e 2007 constituíram em certa medida uma excepção, apresentando uma tendência mais linear do que todos os outros.

O limiar mínimo de área ardida para que um incêndio seja considerado IGM variou de ano para ano, com extremos nos 79,1 ha (1994) e nos 43.282,3 ha (2003) para o período em estudo. Apesar da variabilidade inter-anual que os valores de área ardida por ocorrência apresentam, a grande maioria dos anos origina uma curva de características muito semelhantes (fig. 6), com maior ou menor concentração da área ardida numa minoria de ocorrências mais danosas. É de salientar a semelhança entre curvas relativas a anos em que os valores mínimos de área para definir um IGM são muito diferentes. É o caso, por exemplo, de 1990 (mínimo 157,6 ha), 1998 (1.256,5 ha) e 2003 (43.282,3 ha), o que indica que a relação frequência/importância relativa face ao total de área ardida é, em grande parte, invariante face à magnitude dos incêndios verificados ao longo dos anos. De acordo com esta invariância, a utilização de uma série temporal o mais longa possível, na qual os valores extremos têm portanto relativamente menos peso, tenderá a adequar os limiares de área ardida utilizados ao regime de fogo médio que caracteriza a área de estudo ${ }^{11}$.

11 É importante salientar que, dada a natureza estrutural deste modelo, a noção de IGM não pode ser considerada em termos absolutos para cada ano, o que tornaria discutível a noção implícita de em dois anos sucessivos as áreas percorridas pelo IGM menos danoso poderem variar em duas ou três ordens de magnitude. Trata-se de uma noção que só adquire sentido à escala de um conjunto de anos, para o qual os resultados obtidos serão sobretudo função dos valores de área ardida predominantes. 
Quadro II - Manchas ardidas em IGM no distrito de Castelo Branco (1990-2007). Table II - Burnt patches as a consequence of high magnitude wildfires in the Castelo Branco district (1990-2007).

\begin{tabular}{lccccc}
\hline ANO & $\begin{array}{c}\mathbf{N}^{\mathbf{0}} \text { de manchas } \\
\text { ardidas }\end{array}$ & $\begin{array}{c}\text { \% do } \mathbf{n}^{\mathbf{0}} \text { total de } \\
\text { manchas ardidas }\end{array}$ & $\begin{array}{c}\text { Dimensão } \\
\text { mínima (ha) }\end{array}$ & $\begin{array}{c}\text { Dimensão } \\
\text { máxima (ha) }\end{array}$ & $\begin{array}{c}\text { \% da área } \\
\text { anual ardida }\end{array}$ \\
\hline 1990 & 10 & 22 & 157,6 & 3119,1 & 95 \\
1991 & 14 & 16 & 1044,6 & 11 & 103,5 \\
1992 & 3 & 25 & 226,8 & 1542,1 & 77 \\
1993 & 5 & 56 & 190,5 & 1007,8 & 89 \\
1994 & 6 & 25 & 79,1 & 475,1 & 65 \\
1995 & 12 & 9 & 218,8 & 1345,8 & 62 \\
1996 & 3 & 7 & 394,6 & 2467,0 & 73 \\
1997 & 3 & 11 & 85,6 & 319,4 & 54 \\
1998 & 4 & 8 & 1256,5 & 6845,8 & 82 \\
1999 & 10 & 20 & 251,5 & 2448,9 & 86 \\
2000 & 11 & 16 & 214,2 & 3766,3 & 88 \\
2001 & 5 & 7 & 742,9 & 8652,4 & 87 \\
2002 & 8 & 13 & 615,6 & 4949,9 & 78 \\
2003 & 2 & 4 & 43282,3 & 56550,8 & 82 \\
2004 & 6 & 19 & 474,5 & 3061,2 & 79 \\
2005 & 7 & 17 & 1447,7 & 18741,3 & 93 \\
2006 & 5 & 11 & 128,0 & 1038,4 & 79 \\
2007 & 2 & & 84,9 & 135,6 & 41 \\
\hline
\end{tabular}

\section{Probabilidade Bayesiana}

A abordagem Bayesiana à probabilidade assenta na noção de que o grau de credibilidade associado a uma dada proposição, denominada hipótese, é condicionada por uma ou mais variáveis consideradas como tendo uma relação lógica com essa proposição. Esta aproximação difere da perspectiva frequencista, largamente aceite, que define a probabilidade de ocorrência de um dado acontecimento a partir da observação da sua frequência relativa numa sucessão numerosa de experiências teoricamente idênticas e independentes (Paulino et al., 2003). Segundo o formalismo Bayesiano, $p(h)$ e $p(e)$ são, respectivamente, as probabilidades de que a proposição considerada seja verdadeira, e a probabilidade associada à ocorrência do evento que a condiciona, denominadas a priori. Estas conjugam-se para definir probabilidades condicionadas, denominadas a posteriori: a probabilidade que o evento con- 
dicionante tome lugar dada a verificação da proposição, ou $p(e \mid h)$, e a probabilidade de que se verifique a proposição dada a ocorrência do evento, $p(h \mid e)$, sendo esta última o resultado pretendido. A articulação formaliza-se no Teorema de Bayes:

$$
p(h \mid e)=\frac{p(e \mid h) p(h)}{p(e)}
$$

No presente caso conjugaram-se, para cada ano, as probabilidades a priori $p(A r d), p\left(i_{\text {OcSolo }}\right)$, e $p\left(i_{\text {Decl }}\right)$ que descrevem, respectivamente, a probabilidade de uma dada unidade espacial (pixel) estar integrada numa área ardida num IGM, e numa dada classe $i$ dos temas de declive e ocupação do solo. Da sua articulação resultam:

$$
\begin{aligned}
p\left(\text { Ard } \mid i_{\text {OcSolo }}\right) & =\frac{p\left(i_{\text {OcSolo }} \mid \text { Ard }\right) p(\text { Ard })}{p\left(i_{\text {OcSolo }}\right)} \\
p\left(\text { Ard } \mid i_{\text {Decl }}\right) & =\frac{p\left(i_{\text {Decl }} \mid \text { Ard }\right) p(\text { Ard })}{p\left(i_{\text {Decl }}\right)}
\end{aligned}
$$

descrevendo o grau de plausibilidade associado à proposição de que a unidade espacial, dada a sua classe no tema $j$ (declive ou ocupação do solo), está inserida numa área ardida num incêndio considerado de grande magnitude. Este valor variará entre 0 e 1 .

A partir do cálculo da média dos valores anuais obtidos (anexo 1), foram construídos mapas de susceptibilidade final para as duas variáveis independentes. Estes foram padronizados e integrados através de soma simples. A susceptibilidade final associada a cada pixel consistiu assim em:

$$
\mathrm{Z} \frac{\sum_{A n o=1}^{N} p\left(A r d \mid i_{\text {OcSolo }}\right)}{N}+\mathrm{Z} \frac{\sum_{A n o=1}^{N} p\left(A r d \mid i_{D e c l}\right)}{N}
$$

A fim de construir uma representação cartográfica final (fig. 7), classificaram-se os valores em cinco classes, respeitando o critério oficialmente definido para a cartografia de risco de incêndio (Decreto-Lei n. ${ }^{\circ}$ 124/2006, de 28 de Junho), de forma a que cada classe contenha $20 \%$ das unidades de análise (pixels). A classe de susceptibilidade Muito Alta contém, portanto, os $20 \%$ do distrito considerados mais susceptíveis. Por fim, foram removidas do mapa as classes de ocupação do solo de natureza urbana e as áreas alagadiças e aquáticas, respectivamente os níveis 1,4 e 5 da classificação CORINE. 


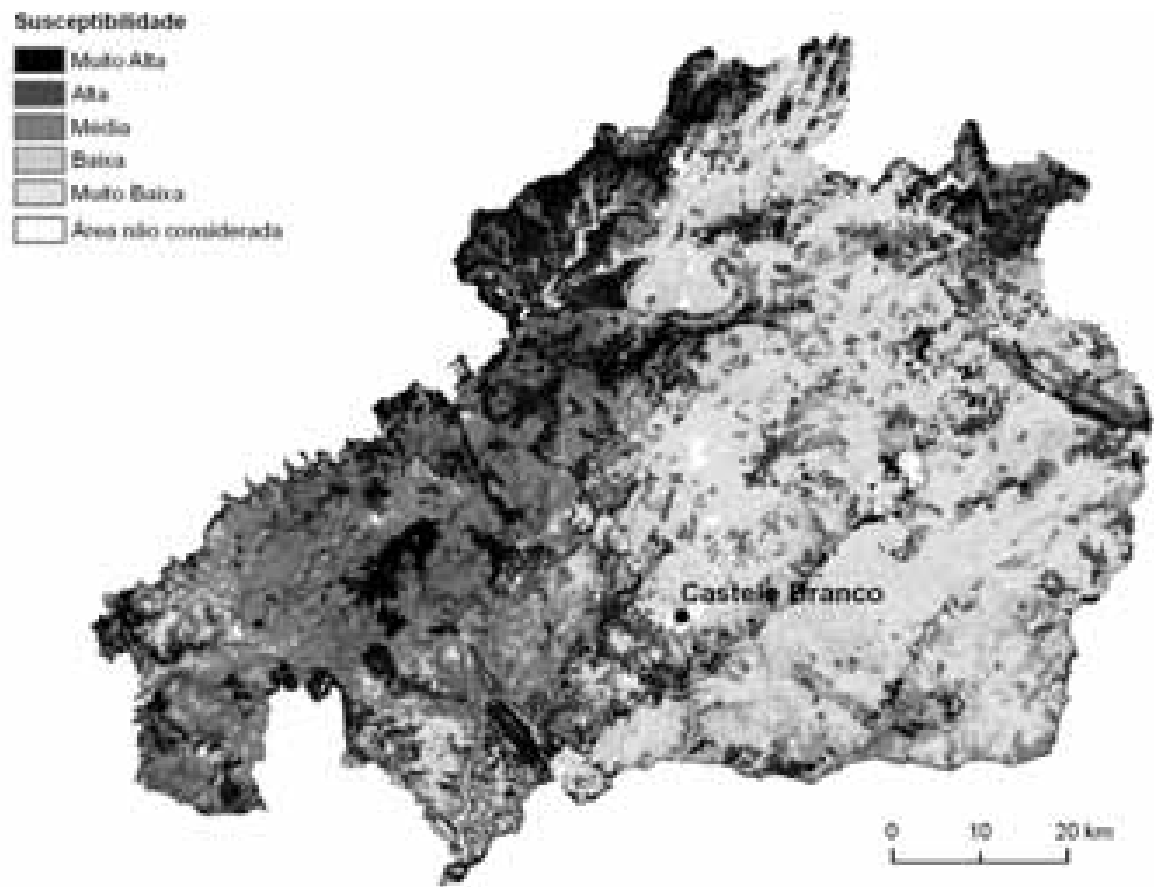

Fig. 7 - Susceptibilidade final segundo a técnica Bayesiana.

Fig. 7 - Final susceptibility map obtained using the Bayesian technique.

\section{Regressão logística}

A regressão logística é uma forma de regressão categorial particularmente adequada a fenómenos que têm expressão em termos de presença/ausência, podendo portanto ser representados na forma de variáveis nominais dicotómicas (Maroco, 2007). Tem sido usada para um conjunto de diferentes fins, de que são exemplo a previsão da distribuição espacial de organismos (Manel et al., 2001, Alvarez-Arbesú e Felicísimo, 2002), ou de propriedades do solo (Gessler et al., 1995).

O modelo de regressão logística pode ser formalizado como:

$$
P(i)=\frac{1}{1+e^{-[b(0)+b(1) x(1)+\ldots+b(n) x(n)]}}
$$

sendo $P(i)$ a probabilidade de presença da classe do fenómeno estudado, $x(1) \ldots$ $x(n)$ os valores (ou as classes) assumidos pelas $n$ variáveis independentes, e $b(1) \ldots b(n)$ os respectivos coeficientes de regressão. O resultado da equação de regressão é um valor de $P(i)$ entre 0 e 1 . 
Num contexto de classificação, pode ser estabelecido um limiar crítico para definir a separação entre presença e ausência, superior ou inferior a 0,5 , consoante o grau de rigor pretendido. No presente trabalho, porém, em que $P(i)$ é encarado como a expressão da propensão para arder, uma variável contínua, 1 foi considerado como a propensão máxima e 0 como a mínima.

Para cada ano do período de modelação foi gerada uma amostra aleatória de 1400 pontos, distribuindo-se pelo menos 700 destes pelas áreas ardidas em IGM (foi gerada uma amostra inicial circunscrita a estas áreas, e uma segunda para toda a área de estudo) ${ }^{12}$. Com base na integração destes pontos com os temas de análise, obtiveram-se doze tabelas anuais, consistindo cada uma destas num conjunto de 1400 combinações entre a instância da variável dependente (1, ardido em IGM, ou 0, não ardido em IGM), e as classes correspondentes das duas variáveis independentes.

Para a obtenção dos valores de susceptibilidade anual $S_{\text {anual }} T i j$, foram realizadas separadamente análises de regressão entre a variável dependente e cada uma das variáveis independentes ${ }^{13}$. A análise permitiu obter, para cada classe, um valor final da probabilidade associada à presença da condição ardido em IGM.

Formalmente, esta probabilidade é descrita por:

$$
\begin{gathered}
P(\text { Ard })_{\text {OcSolo }}=\frac{1}{1+e^{-\left[b(0)+b\left(i_{\text {Ocsolo })}\right)\right.}} \\
P(\text { Ard })_{\text {Decl }}=\frac{1}{1+e^{-\left[b(0)+b\left(i_{\text {Decl }}\right)\right]}}
\end{gathered}
$$

Os valores anuais (anexo 2) foram depois convertidos em valores finais mediante o cálculo da sua média. Estes foram convertidos em dois mapas de susceptibilidade e integrados através de uma soma simples, tendo depois sido removidas as classes de ocupação do solo já referidas (fig. 8).

$$
\frac{\sum_{A n o=1}^{N} P(A r d)_{O c S o l o}}{N}+\frac{\sum_{A n o=1}^{N} P(A r d)_{D e c l}}{N},
$$

12 Foi utilizada a aplicação Random Point Generator, da autoria de M. Sawada (2002), acessível em http://arcscripts.esri.com/details.asp?dbid=12098.

13 A opção pela realização de duas análises univariadas, por oposição a uma bivariada, prendeu-se apenas com a maior facilidade no processamento dos resultados da regressão e na sua integração em temas cartográficos. Não foi assumida a superioridade de um método face ao outro. 


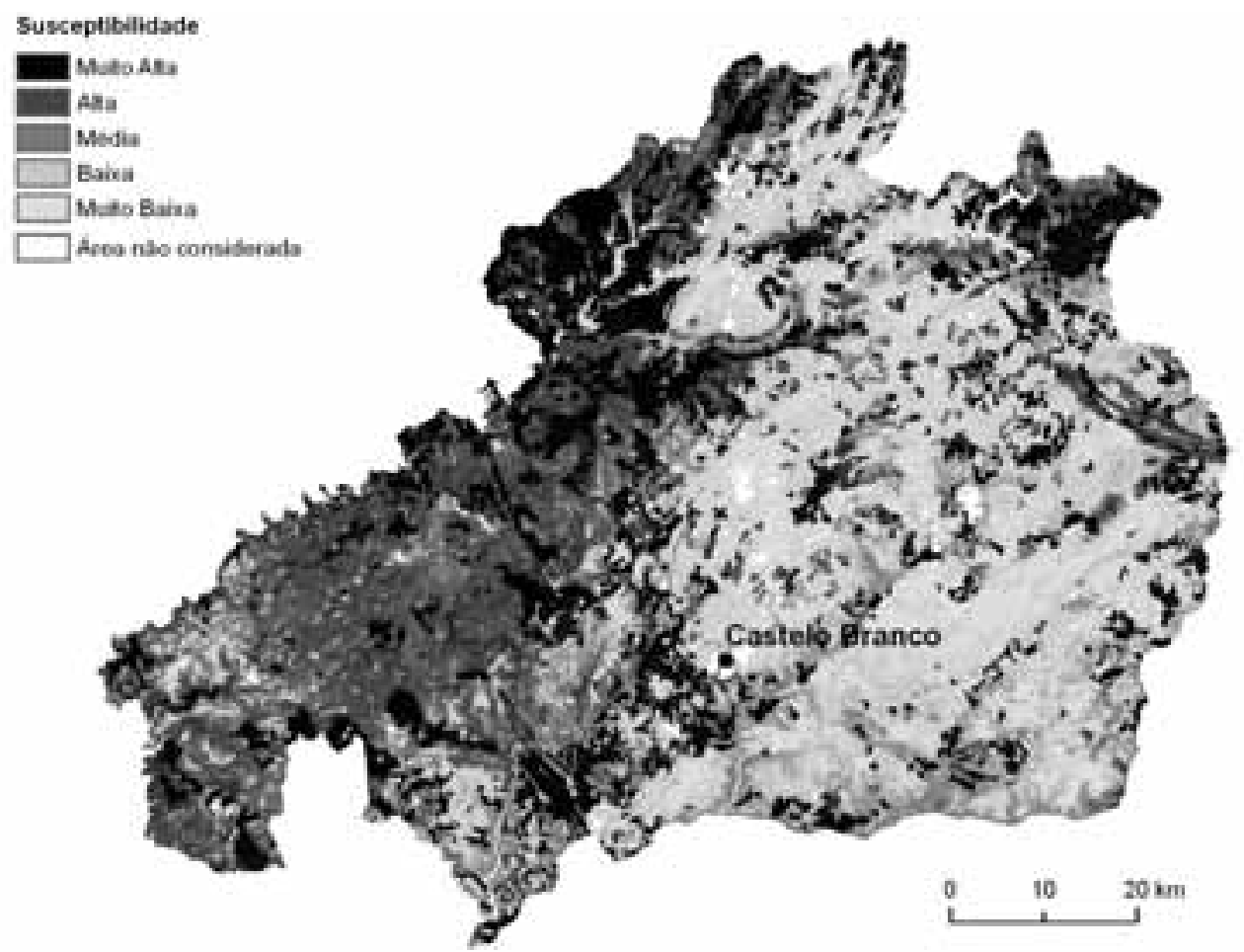

Fig. 8 - Susceptibilidade final segundo a metodologia baseada em Regressão Logística.

Fig. 8 - Final susceptibility pattern obtained with the Logistic Regression technique.

\section{RESULTADOS}

A validação dos dois mapas de susceptibilidade final (figs. 7 e 8) foi realizada através da construção de curvas de predição, resultantes do cruzamento destes com o mapa de áreas ardidas em IGM no período de validação (fig. 9). É de salientar que este último tema cartográfico foi construído através da soma dos mapas de áreas ardidas em IGM em cada ano, expressas como 0 ou 1 (não ardido/ardido). $\mathrm{O}$ resultado foi um mapa único, passível de apresentar valores entre 0 (nunca ardeu num IGM no período 2002-2007) e 6 (ardeu em IGM em todos os seis anos do período), tendo sido obtidos valores entre 0 e 3 . No presente caso, a área que ardeu mais de uma vez tem uma expressão muito reduzida: arderam duas vezes apenas $1,7 \%$ da área total, e três vezes menos de $1 \%$. A opção pela soma dos temas foi justificada pelo facto de a susceptibilidade ser entendida no presente trabalho como estando directamente correlacionada com a recorrência do fogo. Os mapas de susceptibilidade foram assim comparados com todas as unidades espaciais ardidas no período 2002-2007, sendo tidas em conta todas as vezes que arderam. 


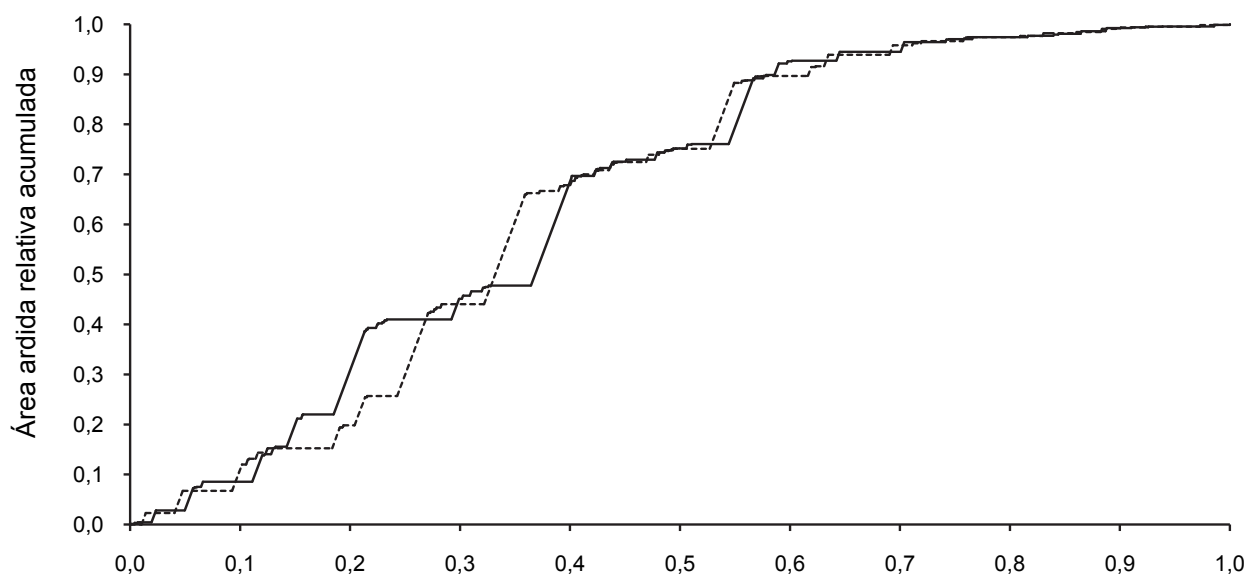

Área relativa acumulada por ordem decrescente de susceptibilidade — Integração Bayesiana Regressão Logística

Fig. 9 - Curvas de predição para o período de validação 2002-2007. Fig. 9 - Prediction curves for the validation period 2002-2007.

De forma a complementar a leitura das curvas, é apresentada no quadro III a correspondência entre proporção de área considerada susceptível e proporção de área ardida.

A análise da figura 9 mostra que, apesar das diferenças entre as duas técnicas, os resultados são bastante semelhantes. A técnica Bayesiana apresenta resultados superiores, revelando ao longo da maioria da distribuição de $x$ valores mais elevados de $y$.

Quadro III - Síntese dos resultados das curvas de predição.

Table III - Synthesis of the results yielded by the prediction curves.

\begin{tabular}{|c|c|c|c|c|c|c|c|c|c|c|}
\hline \multicolumn{2}{|c|}{ Proporção de área mais susceptível } & $\mathbf{0 , 1}$ & 0,2 & $\mathbf{0 , 3}$ & $\mathbf{0 , 4}$ & 0,5 & 0,6 & $\mathbf{0 , 7}$ & $\mathbf{0 , 8}$ & 0,9 \\
\hline \multirow{2}{*}{$\begin{array}{l}\text { Proporção de } \\
\text { área ardida } \\
(2002-2007)\end{array}$} & $\begin{array}{l}\text { Probabilidade } \\
\text { Bayesiana }\end{array}$ & 0,09 & 0,38 & 0,45 & 0,69 & 0,75 & 0,92 & 0,95 & 0,97 & 0,99 \\
\hline & $\begin{array}{l}\text { Regressão } \\
\text { Logística }\end{array}$ & 0,12 & 0,20 & 0,44 & 0,68 & 0,75 & 0,90 & 0,96 & 0,97 & 0,99 \\
\hline
\end{tabular}

É de salientar a notória falta de capacidade preditiva da curva de Regressão Logística até pouco acima dos 0,20 de área mais susceptível, mas é igualmente notável que, apesar de na maioria da distribuição esta técnica se revelar inferior, apresenta em dois intervalos bastante visíveis nos valores de $x$ uma capacidade preditiva significativamente superior à curva Bayesiana (entre os 0,33 e os 0,40 , e entre os 0,54 e os 0,58 ). 
Por último, testaram-se as duas técnicas registando todas as áreas ardidas no período de validação, sem levar em conta a sua magnitude (quadro IV). Procurou-se assim aferir até que ponto os dados revelam um comportamento específico por parte dos IGM.

Quadro IV - Síntese da validação utilizando todas as áreas ardidas no período (2002-2007), não considerando a magnitude.

Table IV - Synthesis of the validation exercise based on the total burnt area (irrespective of the magnitude of the wildfire) during the period (2002-2007).

\begin{tabular}{|c|c|c|c|c|c|c|c|c|c|c|}
\hline \multicolumn{2}{|c|}{ Proporção de área mais susceptível } & 0,1 & 0,2 & $\mathbf{0 , 3}$ & 0,4 & 0,5 & 0,6 & $\mathbf{0 , 7}$ & 0,8 & 0,9 \\
\hline \multirow{2}{*}{$\begin{array}{l}\text { Proporção de } \\
\text { área ardida } \\
(2002-2007)\end{array}$} & $\begin{array}{l}\text { Probabilidade } \\
\text { Bayesiana }\end{array}$ & 0,08 & 0,34 & 0,42 & 0,63 & 0,71 & 0,87 & 0,90 & 0,95 & 0,99 \\
\hline & $\begin{array}{l}\text { Regressão } \\
\text { Logística }\end{array}$ & 0,11 & 0,21 & 0,41 & 0,62 & 0,72 & 0,84 & 0,93 & 0,95 & 0,99 \\
\hline
\end{tabular}

Embora a proporção de área ardida pelos outros incêndios seja na maioria dos anos muito reduzida (quadro II), a associação destes à validação originou redução da capacidade preditiva do modelo, independentemente da técnica utilizada. Os resultados revelam, assim, um ajustamento da metodologia aos incêndios considerados de grande magnitude e, implicitamente, a existência de um comportamento específico por parte destes.

\section{CONCLUSÕES}

De acordo com a metodologia utilizada, a comparação das duas técnicas de integração de dados revelou melhores resultados por parte da Probabilidade Bayesiana, embora tenha ficado claro que a Regressão Logística também se adequa ao fenómeno dos incêndios, numa expressão dicotómica tipo presença/ ausência. Deve ser salientada porém uma diferença importante entre os dois métodos: a Probabilidade Bayesiana foi aplicada a toda a informação de base, enquanto os resultados da Regressão Logística foram forçosamente influenciados pelas características da amostragem. Esta dependência face a uma amostra, embora em nada afecte os resultados obtidos, não permite concluir que a Regressão Logística seja inferior em todas as situações.

Concluiu-se ainda que, com base nos dados utilizados para a área estudada, há um comportamento específico por parte dos IGM, validando a hipótese de trabalho, subjacente à concepção do modelo estrutural de susceptibilidade, com o qual se articularam as duas técnicas testadas.

Embora os resultados tenham sido promissores, ficou também patente que o modelo deverá ser desenvolvido de forma a prever uma proporção superior da área ardida nas áreas consideradas mais susceptíveis, nomeadamente nas duas classes superiores, já que são estas o alvo fundamental das 
medidas preventivas. É importante considerar que, de acordo com o enquadramento conceptual adoptado, o objecto do presente trabalho foi a susceptibilidade do território, nem sempre fácil de isolar da probabilidade de ocorrência de fenómenos perigosos. Futuros desenvolvimentos poderão incluir esta componente probabilística do Perigo, bem como factores de susceptibilidade como a facilidade de detecção inicial, ou do acesso por parte das forças de combate.

De futuro, é também desejável que sejam minoradas as limitações impostas pelos dados. Seria ideal a utilização de uma série temporal mais longa (e portanto mais de acordo com o carácter estrutural do modelo), e a existência de informação actualizada referente à evolução da ocupação do solo durante o período considerado.

A metodologia proposta pretende ter um carácter complementar face às metodologias de avaliação do perigo de incêndio actualmente em uso, sendo a sua contribuição, idealmente, a possibilidade de ajustar as cartografias regionais de forma a acentuar as áreas onde se tende a originar a maioria do dano, por oposição a todas as áreas onde se origina dano. Considerando que uma parte muito significativa das ocorrências anuais tem origem em queimadas (Vieira, 2006; Pereira et al., 2006) e que a grande maioria nunca chega a ultrapassar um hectare de área queimada (op.cit.), a metodologia proposta faz sobressair os locais onde se originam os incêndios mais danosos, reduzindo a influência dos incêndios relativamente menores, e a tendência selectiva que estes apresentam face ao tipo de coberto ardido (Nunes et al., 2005).

Por último, refira-se que o modelo apresenta a vantagem de ser simples de aplicar, utilizando dados facilmente acessíveis aos organismos responsáveis pela gestão do território à escala regional e municipal, bem como dados actualizáveis anualmente.

\section{AGRADECIMENTOS}

Os autores gostariam de agradecer aos dois revisores anónimos, cujos comentários e sugestões beneficiaram o trabalho. R. Bergonse é beneficiário de uma bolsa de investigação da Fundação para a Ciência e Tecnologia (ref. SFRH/BD/46949/2008).

\section{BIBLIOGRAFIA}

Alvarez-Arbesú R, Felicísimo A M (2002) GIS and logistic regression as tools for environmental management: a coastal cliff vegetation model in Northern Spain. In: Brebbia, C A, Pascolo, P (Eds.) Management Information Systems 2002: GIS and Remote Sensing. Wessex Institute of Technology Press: 215-224.

Bachmann A, Allgower B (1999) The need for a consistent wildfire risk terminology. Proceedings from the Joint Fire Science Conference and Workshop, Boise, Idaho, June 15-17. 
Chuvieco E, Congalton R (1989) Application of remote sensing and Geographic Information Systems to forest fire hazard mapping. Remote Sensing of Environment, 29: 147-159.

Durão R, Soares A (2007) Modelo de avaliação de risco de incêndio em Portugal Continental. In Soares C, Teixeira A P, Antão P (Eds.) Riscos Públicos e Industriais. Edições Salamandra, Lisboa: $167-182$.

Gessler P E, Moore I D, Mckenzie N J, Ryan P J (1995) Soil-landscape modelling and spatial prediction of soils' attributes. International Journal of Geographical Information Science, 9 (4): 421-432.

IGP (2008) Cartografia de risco florestal: relatório do distrito de Santarém (versão provisória). http:// scrif.igeo.pt/cartografiacrif/2007/crif07.htm [Acedido em 10 de Janeiro de 09].

ISA (2005) Relatório final da proposta técnica do plano nacional de defesa da floresta contra incêndios. anexo 3: factos e números. Instituto Superior de Agronomia, Lisboa. http://www.isa.utl. pt/pndfci/A3_Factos_Numeros.pdf [Acedido em 02 de Junho de 2008].

ISA (2005b) Relatório final da proposta técnica do plano nacional de defesa da floresta contra incêndios. anexo 8: glossário. Instituto Superior de Agronomia, Lisboa. http://www.isa.utl.pt/ pndfci/A3_Factos_Numeros.pdf [Acedido em 02 de Junho de 2008].

Longley P, Goodchild M, Maguire D, Rhind D (2005) Geographic Information Systems and Science. Wiley.

Lourenço L (2004) Risco meteorológico de incêndio florestal. Coimbra, Colecção Estudos, 46: 167-175.

Manel S, Williams C, Ormerod S J (2001) Evaluating presence-absence models in ecology: the need to account for prevalence. Journal of Applied Ecology, 38: 921-931.

Maroco J (2007) Análise estatística com utilização do SPSS. Edições Sílabo, Lisboa.

Nunes M, Vasconcelos M, Pereira J, Dasgupta N, Alldredge R, Rego F (2005) Land cover type and fire in Portugal: do fires burn land cover selectively? Landscape Ecology, 20: 661-663.

Paulino C, Turkman M A, Murteira B (2003) Estatística Bayesiana. Fundação Calouste Gulbenkian, Lisboa.

Pereira J C P, Santos M T (2003) Áreas queimadas e risco de incêndio florestal em Portugal. DirecçãoGeral das Florestas, Lisboa.

Pereira M G, Trigo R. M., da Câmara C, Pereira J M C, Leite S (2005) Synoptic patterns associated with large summer forest fires in Portugal. Agricultural and Forest Meteorology, 129 (1-2): $11-25$.

Pereira, J M C, Carreiras J M, Silva J M, Vasconcelos M J (2006) Alguns conceitos básicos sobre os fogos rurais em Portugal. In Pereira J S, Pereira J M, Rego F C, Silva J M, Silva T P (Eds.) Incêndios Florestais em Portugal - Caracterização, Impactes e Prevenção. Instituto Superior de Agronomia, Lisboa.

Pyne S (2006) Fogo no jardim: compreensão do contexto dos incêndios em Portugal. In Pereira J S, Pereira J M, Rego F C, Silva J M, Silva T P (Eds.) Incêndios Florestais em Portugal - Caracterização, Impactes e Prevenção. Instituto Superior de Agronomia, Lisboa.

Ramos C, Ventura J E (1992) Um índice climático de perigo de incêndio aplicado aos fogos florestais em Portugal. Finisterra - Revista Portuguesa de Geografia, XXVII (53-54): 79-93.

Strauss D, Bednar L, Mees R (1989) Do one percent of the fires cause ninety-nine percent of the damage? Forest Science, 35: 319-328.

Ventura J, Vasconcelos M (2006) O fogo como processo físico-químico e ecológico. In: Pereira J S, Pereira J M, Rego F C, Silva J M, Silva T P (Eds.) Incêndios Florestais em Portugal - Caracterização, Impactes e Prevenção. Instituto Superior de Agronomia, Lisboa. 
Verde J (2008) Avaliação da perigosidade de incêndio florestal. Dissertação de Mestrado em Geografia Física, Universidade de Lisboa.

Verde J, Zêzere J L (2007) Avaliação da perigosidade de incêndio florestal. Actas do VI Congresso da Geografia Portuguesa, 17-19 de Outubro, Universidade Nova de Lisboa.

Viegas D, Reis R, Cruz M, Viegas M T (2004) Calibração do sistema canadiano de risco de incêndio para aplicação em Portugal. Silva Lusitana 12 (1): 77-93.

Vieira P (2006) Portugal: o vermelho e o negro - a verdade amarga e a dolorosa realidade dos incêndios florestais. Dom Quixote, Lisboa. 


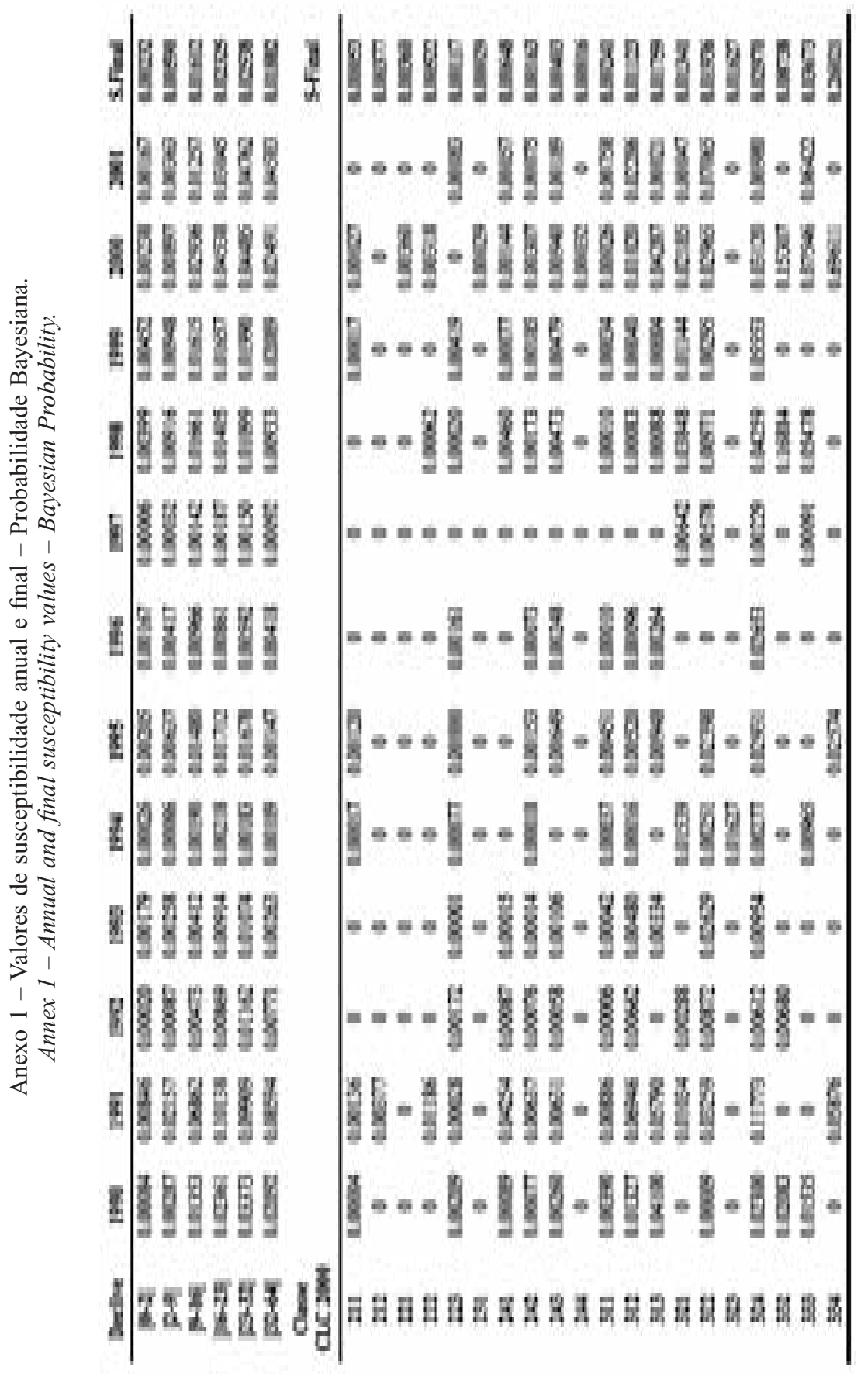




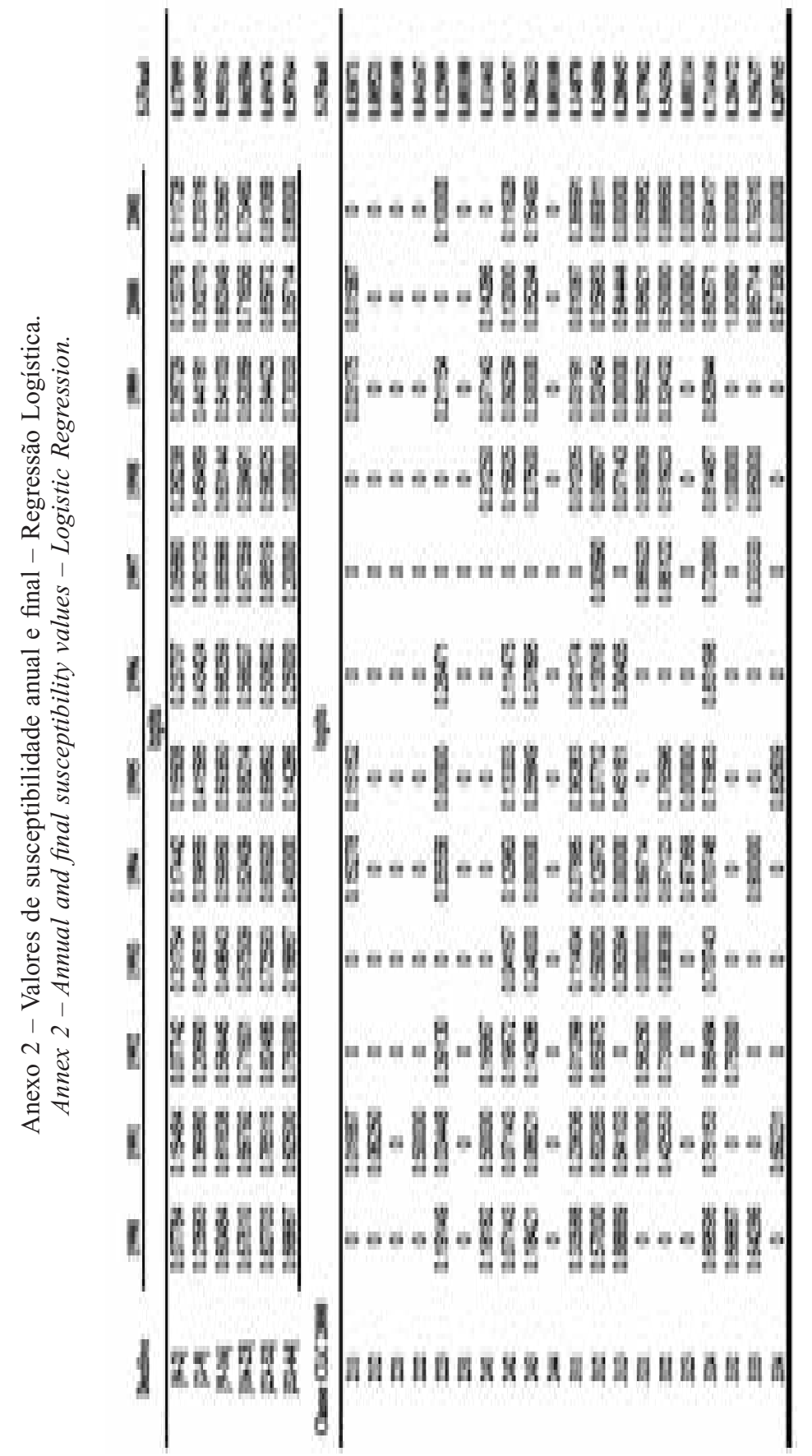

